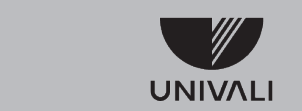

UNIVERSIDADE DO VALE DO ITAJAí

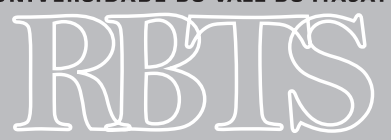

Revista Brasileira

de Tecnologias Sociais
1 Pedagogia (1985), mestranda do Curso de Mestrado Profissional em Gestão de Políticas Públicas na Universidade do Vale do Itajaí-UNIVALI. E-mail: suelimfl@, gmail.com

2 Professor Doutor titular do Curso de Mestrado Profissional em Gestão de Políticas Públicas, na UNIVALI.

3 Professor Doutor titular do Curso de Mestrado Profissional em Gestão de Políticas Públicas, na UNIVALI.

\section{CERTIFICAÇÃO DE QUALIFICACCÃO PROFISSIONAL DOS PESCADORES NO LITORAL DE SANTA CATARINA, BRASIL}

\section{CERTIFICTION OF PROFESSIONAL QUALIFICATION OF FISHERMEN ON THE COAST OF SANTA CATARINA, BRASIL}

\author{
Sueli Maria Furtado Lima ${ }^{1}$ \\ Marco Antonio Harms Dias ${ }^{2}$ \\ JoAQUim Olinto BRANCO ${ }^{3}$
}

RESUMO: Esse artigo analisou o perfil profissional de 68 pescadores envolvidos na política pública Rede Nacional de Certificação Profissional - Certific, na região do Porto pesqueiro de Itajaí, Santa Catarina, entre 2014/2016, a partir de um estudo de caso sobre a experiência de qualificação profissional pelo Instituto Federal de Santa Catarina - IFSC, campus Itajaí. Pode-se concluir que o perfil dos pescadores do curso corresponde ao Certific, sendo que a maioria (70\%) certifica seus saberes, pois trabalhava cerca de 30 anos, sem a documentação exigida, usando subterfúgios para se esquivar da fiscalização, por conta do tempo indisponível para qualificação, tanto que 13\% não puderam concluir o curso, impactando assim a vida dos pescadores e, consequentemente, a pesca, que inclui o Certific como política pública ao setor. A metodologia teve uma abordagem quantitativa, exploratória e descritiva, utilizando o método indutivo-dedutivo, tendo como fonte documentos norteadores do Certific, atas das reuniões de acreditação e normas da Marinha, grupos de trabalhos, plano de desenvolvimento do IFSC, bem como projeto pedagógico e formulário de entrevista profissional semiestruturada do curso.

PALAVRAS-CHAVE: Formação profissional. Certificação profissional. Rede-Certific. Pescador.

ABSTRACT: This article analyzes the professional profiles of 68 fishermen involved in the public policy National Professional Certification Network - Certific, in the fishing port region of Itajaí, Santa Catarina, between 2014/2016, based on a case study on the experience of Professional qualification by the Federal Institute of Santa Catarina-IFSC, Campus Itajaí. We conclude that the profile of the fishermen of the course corresponds to the Certific, with the majority ( $70 \%)$ certifying their knowledge, as they had worked for about 30 years without the required documentation, using subterfuge to avoid supervision due to the unavailable time for Qualification, in such a way that $13 \%$ could not complete the course. This impacted on the fishermen's lives and consequently, the fishing industry itself, which includes the Certific as a public policy for the sector. The methodology used quantitative, exploratory and descriptive approaches, using the inductive-deductive method, based on Certific guideline documents, minutes of the accreditation meetings, Navy regulations, work 
groups, and the development plan of the IFSC, as well as the teaching curriculum and a semi-structured professional interview form of the course.

KEYWORDS: Vocational training. Professional certification. Network-Certific. Fisherman.

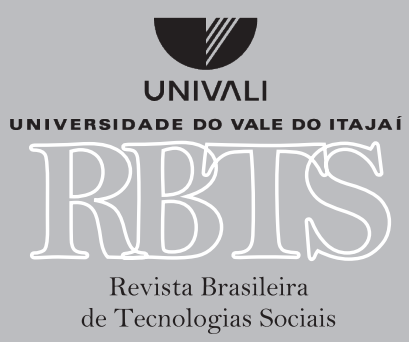




\section{INTRODUÇÃO}

A pesca foi uma das primeiras ações que o homem primitivo desenvolveu para sua sobrevivência. As comunidades dependiam quase que exclusivamente dos recursos naturais por longos períodos, tornando-se motivo de disputas e guerras de confrarias de pescadores, almejando espaços para prática (DIEGUES, 2004). Na medida em que esta atividade crescia, a navegação e a tripulação especializavam-se na busca, cada vez mais distante do pescado, levando ao atual esgotamento dos estoques (BURKE, 1998).

A atual produção nacional de pescado atende uma demanda de 14,4 kg por habitante/ano, acima dos $12 \mathrm{~kg}$ recomendados pela Organização Mundial de Saúde (BRASIL, 2017). Segundo estimativa da Organização das Nações Unidas para Alimentação e Agricultura - FAO, o país deve registrar um crescimento de 104\% na pesca e aquicultura até 2025 (FAO, 2016).

O estado de Santa Catarina possui $531 \mathrm{~km}$ de litoral e é considerado o maior produtor nacional de pescado marinho com 157.223 toneladas. A atividade de pesca industrial de mais de 600 embarcações é responsável por cerca de $20 \%$ da produção nacional de pescado. A descarregada no Porto de Itajaí pelas embarcações provenientes de diversos municípios, Balneário Piçarras, Bombinhas, Itajaí, Itapema, Navegantes, Penha e Porto Belo, fazem desse o maior polo pesqueiro do país (UNIVALI, 2013).

Essa produção vem sendo obtida com o trabalho de aproximadamente seis mil profissionais cadastrados no sindicato de pesca de Santa Catarina, onde o incremento dessa produção demanda profissionais, cada vez mais qualificados, mas muitos ainda exercem ilegalmente a atividade por falta de tempo e escolaridade, contrariando a legislação marítima. Procurando suprir essa lacuna, a política pública de educação profissional da Rede Nacional de Certificação Profissional (Certific) qualificou e certificou esses trabalhadores entre 2014/2016 pelo campus Itajaí do Instituto Federal de Santa Catarina (IFSC).

O IFSC é uma instituição pública federal vinculada ao Ministério da Educação (MEC) por meio da Secretaria de Educação Profissional e Tecnológica (SETEC). O campus Itajaí faz parte da expansão II da rede e desde 2010, atuando na região de abrangência do Porto de Itajaí e ofertando formação profissional (BRASIL, 2008). O Instituto nasceu de uma audiência pública (IFSC, 2009) com foco no arranjo produtivo local dos processos industriais e recursos naturais (produção pesqueira).

Esse trabalho procura analisar o perfil profissional dos pescadores na região de influência do porto pesqueiro de Itajaí, SC, a partir da oferta da política pública da Rede Certific à pesca da região.

\section{METODOLOGIA}

Em um estudo de caso sobre a experiência de certificação de qualificação profissional da Rede Certific, entre 2014/2016, no campus Itajaí, procurou-se analisar o perfil dos pescadores profissionais na região de influência do Porto pesqueiro de Itajaí inscritos no curso. A pesquisa teve uma abordagem quantitativa, exploratória e descritiva (SEVERINO, 2007), utilizando o método indutivo-dedutivo, tendo como fonte documentos norteadores do Certific, atas das reuniões de acreditação e normas da Marinha, grupos de trabalhos, plano de desenvolvimento do IFSC, bem como projetos pedagógicos e formulário de entrevista profissional semiestruturada do curso. 


\section{RESULTADOS E DISCUSSÃO}

\subsection{PERFIL DOS TRABALHADORES}

A Certificação profissional é uma experiência recente no cenário da educação profissional, em que a primeira institucionalização do Certific ocorreu em 2009 e 2011 , sendo implantada por poucos institutos no país, dentre outros, o curso de pesca, pelo Instituto Federal Catarinense, IFC-Araquari (IFSC, 2010). Essa rodada não obteve o êxito esperado (BRASIL, 2014). Após sua implantação, o Certific foi reorganizado em 2014, passando a constituir uma política pública de educação profissional. Essa política tornou-se um instrumento de promoção dos valores democráticos, diante da existência de trabalhadores que não tiveram acesso aos processos formais de aprendizagem com o reconhecimento das suas competências e trajetória de vida (BRASIL, 2014). O IFSC campus Itajaí ofertou entre 2014 a 2016 a certificação de qualificação profissional nas categorias de Pescador Profissional (POP) e Especializado (PEP).

De acordo com os dados dos 68 pescadores entrevistados na admissão do curso, a maioria (86\%) reside na região de abrangência do Porto pesqueiro de Itajaí, é do sexo masculino (94\%), com idade média de 30 anos e variando entre 18 a 55 anos. Esses trabalhadores, em sua maioria, vinham atuando na informalidade e na ilegalidade e, em alguns casos, há 30 anos, precisando de uma terceira pessoa para representá-lo perante a fiscalização, temendo "por não ter liberdade de entrar no porto, sem precisar se esconder” (depoimentos de alunos do curso PEP, 2016).

\subsection{Pescador Profissional e Especializado}

A legislação brasileira reconhece como pescador aquele profissional que faz da pesca seu meio de vida (BRASIL, 2002), mas é o registro geral da atividade pesqueira (RGP) que assegura seu exercício (BRASIL, 1967), a qual é gerida pela licença do Instituto Brasileiro do Meio Ambiente e dos Recursos Naturais Renováveis (IBAMA) e matrícula numa instituição da profissão (sindicato, colônia, associação).

Os alunos que ingressaram no curso buscavam reconhecimento profissional certificado, Caderneta de Inscrição e Registro (CIR), fornecida pela Delegacia da Marinha (BRASIL, 2015a), mas $87 \%$ concluíram o curso e habilitaram-se ao registro legal para trabalhar como aquaviário. Para autoridade marítima, os aquaviários PEPs comandam a embarcação, enquanto os POPs executam as capturas e a conservação do pescado (BRASIL, 2003), usando uma linguagem mais popular, como "mestre de barco", que são em 3.650 POPs e 338 PEPs ativos, conforme dados da Delegacia da Capitania dos Portos em Itajaí.

A escolha da profissão de pescador, segundo os inscritos no curso, foi influenciada pelas gerações de familiares, muitos nunca exerceram outra atividade, passando de aprendiz, pescador, tripulante, gelador, cozinheiro, motorista, contramestre, mestre, nas modalidades de pesca de arrasto simples, duplo e malha. Dessa forma, adquiriram os conhecimentos básicos com a própria experiência vivenciada no trabalho, na qual desenvolveram suas formas e práticas cognitivas, que raramente são acreditadas pelos administradores de pesca (DIEGUES, 2004).

Apenas 22\% dos pescadores inscritos concluíram o ensino fundamental, precisando os conhecimentos adquiridos no senso comum ser certificados e atualizados por meio de qualificação na perspectiva de desenvolvimento sustentável e novas tecnologias, já que todos pretendem 
continuar na profissão. É comum a máxima dos alunos pescadores “Já nasci na pesca e enquanto tiver vida vou estar na pesca”.

A profissão exige tempo integral do pescador, dependendo sempre das condições ambientais para localização, captura e armazenamento do pescado. Assim, o tempo de qualificação é incerto, restrito aos períodos de defeso. Apesar dessa conjuntura, o trabalho é a principal fonte de renda de todos, no qual 45\% dos pescadores recebem em média de dois a sete salários mínimos, utilizados no sustento da família, composta por três a quatro membros.

\section{Políticas Públicas e acReditação pela Marinha}

A pesca alimentou desde os índios, portugueses, até os brasileiros atuais, sem organização ou regulamentação, na vigência da República, foram realizadas outras formas de regularizar a pesca sem continuidade (SANTOS, 1985). Ao longo do tempo, as políticas públicas voltadas à pesca procuram administrar a exploração, concedendo incentivos à produção, por meio da promoção do desenvolvimento da atividade pesqueira no país (ABDALLAH, 1998). Esses investimentos provocaram prejuízos socioambientais, como a superexploração de espécies e conflitos por territórios de pesca (DIEGUES, 1983).

Somente a partir deste século, com a sobrepesca, surge uma nova mentalidade no mundo, determinando o desenvolvimento sustentável da pesca e da aquicultura, como fonte de alimentação, emprego, renda e lazer, garantindo o uso sustentável dos recursos pesqueiros (DIEGUES, 2004), bem como incrementando os benefícios econômicos decorrentes, em harmonia com a preservação, a conservação do meio ambiente e a biodiversidade (BRASIL, 2009).

Com a pesca predatória e o surgimento do período de defeso, o pescador cadastrado é beneficiado pela política distributiva, como seguro-defeso, predeterminando esse tempo para qualificação profissional (BRASIL, 2015b), embora não havendo política pública para esta premissa. Embora, desde 1952, a qualificação para pesca é de exclusiva responsabilidade da Diretoria de Portos e Costas-Marinha do Brasil (BRASIL, 1952), mas somente 30\% dos pescadores inscritos no curso afirmam que foram qualificados por esta instituição. Pela grande demanda, a Marinha acreditou em 2012 outras instituições de ensino, como IFSC, habilitando a ministrar cursos para aquaviários dos $1^{\circ}, 2^{\circ}$ e $3^{\circ}$ grupos, respectivamente marítimos, fluviários e pescadores (BRASIL, 2012). Apesar do Certific não ser uma política pública destinada à pesca, o IFSC de Itajaí buscou na política de educação profissional a solução às demandas emergenciais e urgentes do setor, como a qualificação no escasso tempo do pescador.

\section{ImPLEMENTAÇÃo DO CERTIFIC AOS PESCADORES}

Após Acreditação pela Marinha do Brasil, o IFSC/Itajaí passou a ministrar cursos de qualificação obrigatória aos pescadores, sendo qualificadas mais de 500 pessoas (IFSC, 2017). Contudo, essas medidas ainda não foram suficientes devido à baixa escolaridade e ao tempo disponível para qualificação. A qualificação precisava de um processo inovador que preenchesse a lacuna entre pescador e instituição formadora (Certific). Neste sentido, entre 2014 e 2016, nas cidades de Penha e Itajaí, com os cursos de PEP e POP, o IFSC oportunizou 68 pescadores à qualificação profissional pelo Certific, sendo que $87 \%$ se qualificaram e $70 \%$ certificaram seus saberes, porém pela falta de tempo, $13 \%$ desistiram e $30 \%$ optaram por não se certificar e continuar o curso. 


\section{CONSIDERAÇÕES FINAIS}

O perfil dos pescadores do curso oferecido pelo campus Itajaí corresponde ao da Política Pública de Certificação de Qualificação Profissional (Certific). A maioria (70\%) dos pescadores pôde certificar seus saberes, porque trabalhavam por anos, sem a documentação exigida, esquivando-se da fiscalização, usando subterfúgios, por conta do tempo indisponível para qualificação, tanto que $13 \%$ não puderam concluir o curso. Essa política cumpriu sua função ao reconhecer os saberes em tempo adequado e contribuir com o setor pesqueiro, devolvendo trabalhadores legalizados e qualificados.

A contribuição do IFSC ao setor da pesca na região de Itajaí foi de possibilitar a qualificação com a oferta de cursos que a Marinha do Brasil não ofertava, principalmente como pioneiro no curso para Pescador Especializado no Brasil. Porém, com a expertise, no aproveitamento da política pública de educação profissional da Certificação Profissional para esta área, oportunizando a legalização ao tempo do trabalhador-aluno, também devolveu a dignidade ao pescador de trabalhar tranquilo, ir e vir do porto, sem subterfúgios e assinar por sua profissão. Além disto, os cursos realizados valorizaram o pescador e sua história de vida, aproveitando os conhecimentos adquiridos na trajetória de trabalho e consciência sustentável dos recursos naturais.

\section{REFERÊNCIAS}

ABDALLAH, P. R. Atividade pesqueira no Brasil: política e evolução. Tese de Doutorado - Universidade de São Paulo. São Paulo, 1998.

BRASIL. CERTIFIC: rede nacional de Certificação profissional. Brasília: Ministério do trabalho e emprego e Ministério da Educação. 2014. Disponível em: <http://www.ifsc.edu.br/arquivos/proeja/ Rede\%20Certific_Documento\%20Orientador2014.pdf>. Acesso em: 29 set. 2016.

BRASIL. Decreto $\mathbf{n}^{\mathbf{o}} \mathbf{2 2 1}$, de 28 de fevereiro de 1967. Regula e estimula a pesca. Brasília, DF, 28 fev. 1967. Disponível em: <http://www.planalto.gov.br/ccivil_03/decreto-lei/Delo22 1compilado.htm>. Acesso em: 29 set. 2016.

BRASIL. Decreto $\mathbf{n}^{\mathbf{0}} \mathbf{8 . 6 0 5}$, de 18 de dezembro de 2015. Promulga a Convenção no-185 (revisada) da Organização Internacional do Trabalho - OIT e anexos, adotada durante a $91^{\underline{a}}$ Conferência Internacional do Trabalho, realizada em 2003, que trata do novo documento de Identidade do Trabalhador Marítimo. Disponível em: <http://legislacao.planalto.gov.br/legisla/legislacao.nsf/Viw_Identificacao/DEC\%20 8.605-2015>. Acesso em: 11 jul. 2017.

BRASIL. Lei no 1.658, de 4 de agosto de 1952. Dá nova organização administrativa ao Ministério da Marinha. Rio de Janeiro, em 4 de agosto de 1952. Disponível em <http://www.planalto.gov.br/ccivil_03/ leis/1950-1969/L1658.htm>. Acesso em: 28 jun. 2017.

BRASIL. Lei $\mathbf{N}^{\mathbf{0}} \mathbf{1 1 . 8 9 2}$, de 29 de dezembro de 2008. Institui a Rede Federal de Educação Profissional, Científica e Tecnológica. Brasília, DF, 29 dez. 2008. Disponível em: <http://www.planalto.gov.br/ ccivil_03/_ato2007-2010/2008/lei/11 1892.htm>. Acesso em: 03 fev. 2017.

BRASIL. Lei $\mathbf{n}^{\mathbf{0}} \mathbf{1 1 . 9 5 9}$, de 29 de junho de 2009. Dispõe sobre a Política Nacional de Desenvolvimento Sustentável da Aquicultura e da Pesca, regula as atividades pesqueiras, revoga a Lei no 7.679, de 23 de novembro de 1988, e dispositivo do Decreto-Lei n 22 1, de 28 de fevereiro de 1967, e dá outras providências. Brasília, DF, 29 jun. 2009. Disponível em: < http://www.planalto.gov.br/ccivil_03/_ato2007-2010/2009/ Lei/L11959.htm>. Acesso em: 29 set. 2016. 
BRASIL. Lei no 13.134, de 16 de junho de 2015. Altera as Leis no 7.998/1990, que regula o Programa do Seguro-Desemprego e o Abono Salarial e institui o Fundo de Amparo ao Trabalhador (FAT), no 10.779 / 2003, que dispõe sobre o seguro-desemprego para o pescador artesanal, e no 8.213/1991, que dispõe sobre os planos de benefícios da Previdência Social; revoga dispositivos da Lei no 7.998/1990, e as Leis no 7.859/1989, e no 8.900/1994; e dá outras providências. Brasília, DF. 2015b. Disponível em: <http:// www.planalto.gov.br/ccivil_03/_Ato2015-2018/2015/Lei/L13134.htm>. Acesso em: 29 set. 2016.

BRASIL, Marinha do. Cooperação Técnica Marinha e IFSC. 2012. Disponível em: <https://www.dpc. mar.mil.br/sites/default/files/sepm/aquaviarios/cooperacao_tecnica/act_ifsc.pdf>. Acesso em: 20 set. 2016.

BRASIL, Marinha do. Normas da autoridade marítima para aquaviários NORMAM-13/DPC - 2003. Disponível em: <https://www.dpc.mar.mil.br/sites/default/files/normam30.pdf>. Acesso em: 24 nov. 2016.

BRASIL, Ministério Trabalho e Emprego-TEM. Portaria n 397, de 09 de outubro de 2002 Aprova a Classificação Brasileira de Ocupações - CBO/2002, para uso em todo território nacional e autoriza a sua publicação. Classificação Brasileira de Ocupações, versão 2002. Disponível em: <http://www.mtecbo.gov.br/cbosite/pages/regulamentacao.jsf\#p>. Acesso em: 25 nov. 2016.

BRASIL, Portal. Produção de peixes no Brasil cresce com apoio de pesquisas da Embrapa. 2017. Todo o conteúdo deste site está publicado sob a licença Creative Commons CC BY ND 3.0 Brasil. Disponível em: <http://www.brasil.gov.br/economia-e-emprego/2017/o1/producaode-peixes-no-brasil-cresce-com-apoio-de-pesquisas-da-embrapa>. Acesso em: 14 jul. 2017.

BURKE, J. O presente do fazedor de machados: os dois gumes da história da cultura humana. Rio de Janeiro: Bertrand Brasil, 1998.

DIEGUES, A.C. Pescadores, camponeses, e trabalhadores do mar. São Paulo: Ática, 1983.

DIEGUES, A.C. A pesca construindo sociedades: Leitura em antropologias marítima e pesqueira. São Paulo, 2004.

INSTITUTO FEDERAL DE CATARINENSE. Edital n019/2010. Dispõe sobre as datas e procedimentos para inscrição para o processo de reconhecimento de saberes para fins de certificação profissional e ingresso em cursos de formação inicial e continuada de trabalhadores nos programas interinstitucionais da rede CERTIFIC-PESCA.2010. Disponível em: <http:// editais.araquari.ifc.edu.br/wp-content/uploads/sites/5/2013/09/editalo19_certific.pdf $>$. Acesso em: 03 dez 2016.

INSTITUTO FEDERAL DE SANTA CATARINA. Anuário estatístico 2017. Disponível em <http://www.ifsc.edu.br/anuario-estatistico>. Acesso em: 11 jul. 2017.

INSTITUTO FEDERAL DE SANTA CATARINA. Formulário de entrevista profissional semiestruturada do curso PEP. 2015.

INSTITUTO FEDERAL DE SANTA CATARINA. Notícia: Audiência pública vai definir cursos da unidade de Xanxerê.2009. Disponível em: <http://www.ifsc.edu.br/mais-noticias/9noticias/609-2702-audiencia-publica-vai-definir-cursos-da-unidade-de-xanxere $>$. Acesso em: 08 maio 2017.

INSTITUTO FEDERAL DE SANTA CATARINA. Notícia: 07.10. IFSC inicia processo de reconhecimento de saberes do Programa Certific. 2011 . Disponível em $<$ http://www.ifsc.edu. 
br/9-noticias/1958-07 10-if-sc-inicia-processo-de-reconhecimento-de-saberes-do-programaCertific>. Acesso em: 08 maio 2017.

ORGANIZAÇÃO DAS NAÇÕES UNIDAS PARA ALIMENTAÇÃO E AGRICULTURAFAO, 2016. Relatório: The State of World Fisheries and Aquaculture; Páginas: \#253 p. ISBN: 978-92-5-309185-0. Número de trabalho: I5555; Oficina: Fisheries and Aquaculture Department. Disponível em: <http://seafoodbrasil.com.br/wp-content/uploads/2016/07/SOFIA2016_ resumo.pdf>. Acesso em: 13 dez. 2016.

SANTOS, E. Pesca e piscicultura. 2. ed. Belo Horizonte: Itatiaia Limitada, 1985.

SEVERINO, A. J. Metodologia do trabalho científico. 23. ed. São Paulo: Cortez, 2007.

UNIVAli/CTTMar, 2013. Boletim estatístico da pesca industrial de Santa Catarina. Ano 2012. Universidade do Vale do Itajaí, Centro de Ciências Tecnológicas da Terra e do Mar, Itajaí, SC. Volume 13, número 1, 66 p. Disponível em: <http://www.icmbio.gov.br/cepsul/images/ stories/biblioteca/download/estatistica/SC/est_2012_producao_pesqueira.pdf>. Acesso em: 13 dez. 2016. 